\title{
Câmara de Resolução de Litígios de Saúde do Rio de Janeiro: Reflexões e Perplexidades a partir de uma Aproximação Empírica
}

\author{
Rio de Janeiro's Health Disputes Resolution Chamber: \\ Reflections and Perplexities from an Empirical Approach
}

Klever Paulo Leal Filpo ${ }^{1}$

Felipe Dutra Asensi ${ }^{2}$

\section{RESUMO}

O artigo explora dados de pesquisa realizada entre maio de 2019 e maio de 2020 por meio de uma aproximação empírica, de natureza qualitativa, da Câmara de Resolução de Litígios de Saúde (CRLS) situada no centro da cidade do Rio de Janeiro. Trata-se de uma iniciativa que envolve vários atores institucionais, sendo identificada como um meio de resolução de conflitos sanitários destinado a evitar a judicialização de demandas de saúde pelos assistidos da Defensoria Pública. O trabalho descreve as etapas da implantação e o funcionamento da CRLS. Também busca problematizar e refletir sobre os dados levantados, inicialmente em fontes bibliográficas e documentais e, em um segundo momento, em observações de campo. Concluiuse que a iniciativa traz bons resultados do ponto de vista institucional, sendo apresentada como um caminho alternativo à judicialização. Contudo, também gera perplexidades e suscita reflexões por conta do predomínio da perspectiva institucional sobre a perspectiva dos usuários, sobretudo pobres e doentes, e do fortalecimento do discurso da harmonia no campo das demandas de saúde pública, no Brasil.

\section{PALAVRAS-CHAVE:}

Saúde Pública; Judicialização da Saúde; Mediação Sanitária; Pesquisa Empírica.

\begin{abstract}
The paper explores research data collected between May 2019 and May 2020 through an empirical approach of the Health Dispute Resolution Chamber (CRLS) located in the center of Rio de Janeiro city. It is an initiative that involves several institutional actors, identified as new way to resolve health conflicts and to avoid health demands judicialization by those assisted by the Public Defender's Office. The text describes the implementation of this Chamber and its proceedings. It also seeks to problematize and reflect on the data collected, initially in bibliographic and documentary sources and, in a second moment, through field observations.

\footnotetext{
${ }^{1}$ Doutor em Direito. Professor do Programa de Pós-graduação em Direito da Universidade Católica de Petrópolis. Professor da Graduação em Direito da Universidade Federal Rural do Rio de Janeiro - Instituto Três Rios. Pesquisador do INCT/InEAC/UFF.

${ }^{2}$ Pós-Doutor em Direito pela Universidade do Estado do Rio de Janeiro (UERJ). Doutor em Sociologia pelo Instituto de Estudos Sociais e Políticos (IESP/UERJ). Mestre em Sociologia pelo Instituto Universitário de Pesquisas do Rio de Janeiro (IUPERJ). Professor do Programa de Pós-graduação em Direito da Universidade Católica de Petrópolis e do Instituto de Medicina Social da Universidade do Estado do Rio de Janeiro.
} 
The research shows that the initiative brings good results from an institutional point of view, presented as an alternative path to health judicialization. However, it also generates perplexities and raises reflections due to the predominance of the institutional perspective over the perspective of users, especially poor and sick people, and the strengthening of the discourse of harmony in the field of public health demands, in Brazil.

\section{KEYWORDS:}

Public Health; Health Judicialization; Sanitary Mediation; Empirical Research.

\section{INTRODUÇÃO}

Este artigo tem por objetivo compartilhar perplexidades empíricas e suscitar reflexões a respeito da Câmara de Resolução de Litígios de Saúde do Rio de Janeiro (CRLS/RJ). A expressão litígios de saúde é aqui empregada para fazer referência às disputas surgidas quando os cidadãos que necessitam de determinada prestação positiva no campo da saúde pública (entrega de remédios, insumos, realização de exames e cirurgias, dentre outros), têm esta pretensão negada pela administração pública, dando origem a um conflito de interesses.

Motivada pelos índices crescentes de judicialização de conflitos dessa natureza no estado do Rio de Janeiro, a Procuradora Geral do Estado ${ }^{3}$ e outras instituições, da forma que será melhor explicitada adiante, instituíram a CRLS, destinada a buscar soluções consensuais para conflitos entre cidadãos e entes estatais com o objetivo declarado de reduzir a propositura de ações judiciais ligadas à saúde pública.

O problema da pesquisa pode ser expresso por meio de algumas perguntas, a saber: como funciona a CRLS do Rio de Janeiro? Quais são as dificuldades e obstáculos observados no seu funcionamento? Que reflexões podemos fazer a respeito desse serviço, a partir de uma aproximação empírica? Desde o início chamou nossa atenção, de forma especial, o fato desse

3 “A Procuradoria Geral do Estado é o órgão responsável pela representação judicial e consultoria jurídica do Estado do Rio de Janeiro. Suas principais atribuições estão previstas no art. 132 da Constituição Federal e no artigo 176 da Constituição do Estado do Rio de Janeiro, destacando-se as de funcionar como órgão central do sistema jurídico estadual”. Informações disponíveis em: <https://www.govserv.org/BR/Rio-deJaneiro/326410284082239/Procuradoria-Geral-do-Estado-do-Rio-de-Janeiro>. Acesso em 05 jun. 2020. 
serviço ser procurado por pessoas doentes e suas famílias, em busca de alguma providência no campo da saúde, ao passo em que os idealizadores da CRLS são representantes dos próprios entes encarregados constitucionalmente de concretizar o direito à saúde pela via administrativa (Município, Estado, União) ou pela via judicial (Defensorias Públicas e Tribunais) situação capaz de gerar algumas perplexidades. Voltaremos a esse ponto mais adiante.

A opção metodológica foi por um trabalho de inspiração etnográfica (MALINOWSKI, 1978), "método" " de pesquisa empírica qualitativa que apanhamos "emprestado" da antropologia, envolvendo o trabalho de campo, observações, entrevistas, descrição e análise de situações observadas. Considerando que a área do Direito parece mais familiarizada e limitada às revisões bibliográficas como forma de produção e reprodução do conhecimento (KANT DE LIMA, 2009), essa opção pareceu conferir certa originalidade à pesquisa. Posteriormente, localizamos outros trabalhos enfocando o mesmo objeto (SOARES, 2017 e SOUZA, 2016), privilegiando a perspectiva institucional, os quais serão referidos mais adiante. Além de observações de campo este trabalho também contém dados levantados por meio de revisão bibliográfica e outros encontrados nas páginas (websites) institucionais, das entidades envolvidas no projeto da CRLS.

O objetivo do artigo é colocar sob discussão alguns dados obtidos na pesquisa e, assim, contribuir para a discutir métodos de administração de conflitos em espaços extrajudiciais, de forma consensual, em consonância com as iniciativas legislativas que serão apontadas mais adiante e com a Política Judiciária Nacional de Tratamento Adequado dos Conflitos de Interesse, observando mais de perto a possibilidade de sua aplicação para a administração de conflitos de saúde - explorando limites, possibilidades e, sobretudo, estranhamentos.

\footnotetext{
${ }^{4}$ Entre aspas porque, embora frequentemente apontada como um método próprio dos antropólogos, fomos alertados por Peirano (2014) sobre um outro ponto de vista. Para ela, "Etnografia não é método". Nesse texto a autora considera que "a pesquisa de campo não tem momento certo para começar e acabar. Esses momentos são arbitrários por definição e dependem (...) da potencialidade de estranhamento, do insólito da experiência, da necessidade de examinar por que alguns eventos, vividos ou observados, nos surpreendem. E é assim que nos tornamos agentes na etnografia, não apenas como investigadores, mas nativos/etnógrafos. Essa dimensão incita ao questionamento da etnografia como método."
} 


\section{OPÇÕES METODOLÓGICAS E DIFICULDADES ENCONTRADAS}

A pesquisa propriamente dita $^{5}$ foi iniciada com um levantamento de materiais de divulgação da CRLS encontrados em diversificados veículos de comunicação, sobretudo páginas eletrônicas (sites oficiais) das instituições envolvidas na concepção e operação da Câmara; de textos publicados sobre o assunto, acadêmicos e não acadêmicos; além de dissertações de mestrado que tomaram a CRLS como objeto de investigação.

Percebemos que o discurso existente acerca do funcionamento da CRLS - não apenas predominante, mas hegemônico - é o discurso institucional. Notamos, nessa etapa da pesquisa e por meio dessas fontes, uma certa uniformidade no modo como a iniciativa foi/é apresentada ao público em geral, ressaltando a característica inovadora do trabalho que ali se pretende desenvolver, bem como as supostas vantagens de se solucionar uma demanda individual de saúde pública por meio de métodos consensuais, em vez de partir para a sua judicialização. Nesse caso, o método consensual proposto corresponde ao protocolo adotado para o atendimento dos assistidos das Defensorias na CRLS.

Em um segundo momento, realizamos uma aproximação empírica da CRLS a fim de observar o seu funcionamento e interagir com alguns dos seus atores ${ }^{6}$. Durante nossas incursões de campo, ocorridas em três oportunidades entre maio de 2019 e março de 2020, realizamos observações e entrevistas informais na sede situada no centro da cidade do Rio de Janeiro, mais especificamente na Rua da Assembleia 77-A, em prédio desapropriado especificamente para a instalação da referida Câmara. Essa experiência e seus resultados serão descritos mais adiante.

A respeito dessa abordagem qualitiativa que pretendemos realizar, um questionamento feito frequentemente diz respeito à dúvida quanto à validade dos dados resultantes de um trabalho de campo desenvolvido por um único pesquisador empírico. Embora esse não seja um

5 Este artigo é resultado de pesquisa desenvolvida no âmbito de estágio Pós-Doutoral realizado no Instituto de Medicina Social da Universidade do Estado do Rio de Janeiro pelo autor Klever Paulo Leal Filpo, Supervisionado pelo Prof. Dr Felipe Dutra Asensi.

6 Tendo em vista das regras estabelecidas para assegurar a ética das pesquisa científicas, registramos que a resolução 510 do CNS ressalva hipóteses de pesquisas em Ciências Humanas e Sociais cujos procedimentos metodológicos envolvam a utilização de dados diretamente obtidos com os participantes, apontando que não serão registradas nem avaliadas pelo sistema CEP/CONEP pesquisas de opinião pública com participantes não identificados, bem como pesquisas que utilizem informações de domínio público, nos termos dos incisos I e III do parágrafo único do artigo $1^{\circ}$ da citada resolução 510. Disponível em < http://www.conselho.saude.gov.br/resolucoes/2016/Reso510.pdf>. Acesso em 10 abr. 2020. 
problema no campo da antropologia - dada a sua longa tradição etnográfica (OLIVEIRA, 1996) - a questão parece surgir quando os trabalhos etnográficos (ou de inspiração etnográfica) chegam a outros campos como, por exemplo, o do Direito. Ou, no caso desta pesquisa específica, no campo da saúde pública. A indagação se aplica pela pretensão de compreender o funcionamento da CRLS a partir de uma experiência de campo limitada no tempo e no espaço, em que tivemos a oportunidade de observar parcialmente o seu funcionamento e interagir com apenas alguns dos seus atores.

A esse respeito, Esperidião e Trad (2005) explicam que, ao contrário do que se possa imaginar, embora as técnicas qualitativas se valham de uma amostra reduzida de sujeitos, elas não produzem, necessariamente, medidas exclusivamente individuais. "Teóricos sociais têm mostrado que falas individuais são tecidas de material ideológico; são tramas de todas as relações e acompanham as mudanças sociais de um grupo" (ESPERIDIÃO e TRAD, 2005, p. 305). Portanto - concluem as autoras - em apenas uma fala pode estar contida toda a representação de grupos determinados em condições históricas, econômicas e culturais específicas.

Algumas dificuldades foram encontradas nesse percurso. A primeira delas disse respeito à aproximação institucional, já que as atividades ali realizadas, a exemplo do que ocorre com a mediação de conflitos (Lei 13.140/15), são consideradas confidenciais. Essa confidencialidade é um obstáculo contornável apenas por meio de autorizações especiais (por exemplo, a autorização da Secretaria Estadual de Saúde obtida por SOARES, 2017, p. 96). À míngua de uma semelhante autorização, nosso ingresso no campo não se mostrou tão simples. Em uma de nossas incursões na CRLS percebemos que a presença de pessoas "estranhas" - afora os usuários e seus acompanhantes ou quadros internos - não é exatamente bem vinda, a despeito de se tratar de um serviço público.

Durante a pesquisa de campo, ocorreu de um dos pesquisadores estar sentado em silêncio na sala de espera para a triagem e ser indagado pela recepcionista sobre o que estava fazendo ali. Ao explicar que estava apenas esperando, isso deixou a atendente incomodada de modo que, passados alguns minutos, ela voltou a indagar as razões da sua presença. Também perguntou se era advogado, obtendo resposta afirmativa. Nesse momento sinalizou que não era para um advogado estar ali, dizendo algo como "advogado, aqui? Aqui não precisa advogado, aqui é Defensoria". Um tanto constrangido, o pesquisador deixou a sala depois de alguns minutos. 
Posteriormente, soubemos que no ano de 2018 houve ruídos institucionais entre a Ordem dos Advogados do Brasil e a CRLS, conforme notícia publicada no site da OAB/RJ em 10 de agosto de $2018^{7}$, gerando uma aparente animosidade entre advogados e gestores da CRLS. Uma comitiva da Comissão de Prerrogativas da Ordem compareceu à Câmara, onde foi recebida pelas respectivas coordenadoras, reivindicando que os usuários e, eventualmente, respectivos advogados que desejassem constituir para realizarem a defesa de seus interesses em juízo pudessem ter acesso aos documentos pertinentes ao atendimento, especialmente relatórios médicos que viessem a ser emitidos, de modo a instruir (a expressão utilizada na notícia é “municiar”) eventual ação judicial ${ }^{8}$.

Embora não fosse objeto primeiro da pesquisa explorar esses ruídos institucionais, eles acabaram aparecendo e interferiram no seu desenvolvimento. De um lado, a postura de fechamento das atividades da Câmara em uma espécie de redoma institucional e institucionalizada pode dificultar o exercício do controle social necessário por se tratar de um serviço público destinado ao atendimento das demandas de saúde de pessoas pobres e doentes, arranhando a transparência que todo serviço público, segundo a lei, deve observar. De outro lado, o acesso aos dados de campo, da forma como vislumbramos inicialmente, ficou prejudicado.

Finalmente, a partir de março de 2020, o sistema de saúde pública em todos os níveis voltou-se prioritariamente para o enfrentamento da COVID-19, fator este que, juntamente com o advento das medidas de isolamento social destinadas a conter a propagação do vírus, tornaram impossível o prosseguimento da pesquisa de campo.

Essas dificuldades foram contornadas com a intensificação da pesquisa em fontes bibliográficas e documentais, de forma complementar ao trabalho de campo. Foi esse acervo de dados que nos oportunizou as reflexões apresentadas neste artigo.

\footnotetext{
7 Notícia publicada em https://oabrj.org.br/noticias/oabrj-pede-acesso-camara-resolucao-litigios-relacionados-aosus. Acesso em 10 fev. 2020.

8 Ainda segundo a notícia divulgada pela $\mathrm{OAB}$, as coordenadoras da CRLS informaram que "o assistido não ganha acesso prévio ao parecer técnico que embasa tais processos", entendimento este que os representantes da OAB avaliaram como uma forma de "alijamento" da atuação de advogados e "violação de prerrogativas", por entenderem ter "direito de examinar, em qualquer órgão dos poderes judiciário e legislativo ou da administração pública, autos de processos findos ou em andamento (Art. 7, inc. XIII do Estatuto da Advocacia)".
} 


\section{SOBRE SOLUÇÕES CONSENSUAIS PARA CONFLITOS SANITÁRIOS}

A adoção de serviços voltados à solução consensual de disputas no âmbito da CRLS se apresenta como uma contribuição relevante, do ponto de vista de duas políticas públicas concebidas e estimuladas pelo Conselho Nacional de Justiça: (i) a Política Judiciária Nacional para a Saúde (ASENSI; PINHEIRO, 2015, p. 12), relacionada ao tema da judicialização da saúde e as respostas institucionais, do Poder Judiciário, em vista desse fenômeno; e (ii) a Política Judiciária Nacional de Tratamento Adequado de Conflitos de Interesse pelo Poder Judiciário, esta última inaugurada com a Resolução 125 do CNJ/2010 que pretendeu estimular a utilização de meios consensuais, como a conciliação e a mediação, em diferentes contextos (MELLO; BAPTISTA, 2011): questões de família, empresariais, desportivas - ou mesmo sanitárias, no caso deste artigo.

Essa assertiva parece verdadeira ainda que as práticas levadas a efeito na CRLS não se encaixem tão facilmente nos rótulos de mediação ou conciliação, guardando alguma semelhança com o modelo de "mesas de negociação", como apontado por Delduque e Castro (2015) em vista do artigo $1^{\circ}$ do Decreto 8.243/2014, que as define como "mecanismo de debate e de negociação com a participação dos setores da sociedade civil e do governo diretamente envolvidos no intuito de prevenir, mediar e solucionar conflitos sociais".

Pesquisas anteriores (por exemplo, MEIRELLES e MIRANDA NETTO, 2014; DUARTE et al, 2017), apontam ser impossível estabelecer uma forma única e rígida de "mediação". São fazeres e saberes que vão sendo construídos de forma um tanto autêntica, fluida e independente, pelos atores e instituições envolvidos. A forma estabelecida pela Lei 13.140/15 é apenas uma das que pode vir a ser encontrada no campo empírico, já que se trata de uma ferramenta informal de administração de conflitos. Com efeito, essa lei contempla um espectro bastante amplo de possibilidades ${ }^{9}$. Por isso alguns falam em "mediações", e não em “mediação” (MEIRELLES e MIRANDA NETTO, 2014).

\footnotetext{
${ }^{9}$ Segundo a lei 13.140/15, mediação é "a atividade técnica exercida por terceiro imparcial sem poder decisório, que, escolhido ou aceito pelas partes, as auxilia e estimula a identificar ou desenvolver soluções consensuais para a controvérsia". Ou seja, um método prioritariamente extrajudicial usado para resolver conflitos, externo ao Poder Judiciário, a princípio.
} 
No mesmo sentido, em pesquisa sobre o serviço de mediação oferecido na Rocinha, Rio de Janeiro, pelas Unidades de Polícia Pacificadora então instaladas naquela comunidade, Romaneli e Baptista (2017) perceberam que a mediação não é uma categoria unívoca, apresentando diversos sentidos e representações, dependendo da natureza do conflito e do espaço e atores envolvidos em sua administração. Logo - concluem as autoras - o estudo da mediação de conflitos não deve estar restrito às páginas dos manuais da dogmática, pois a sua análise meramente discursiva não permite apreender suas múltiplas interpretações e apropriações, que são explicitadas através da observação de suas práticas (ROMANELI; BAPTISTA, 2017).

Curiosamente o maior protagonista no estímulo ao consenso como alternativa à judicialização vem sendo o próprio Poder Judiciário desde a criação do Conselho Nacional de Justiça (2004), consolidando-se a partir da Res. 125 desse Conselho (NUNES, 2014). Sob a ótica dos Tribunais, parece haver a intenção de evitar a que as disputas cheguem às suas barras, preferindo que estas sejam solucionadas por outras vias, como a mediação extrajudicial (FILPO, 2016).

Desde esse primeiro “disparador”, que partiu do Poder Judiciário, tem-se buscado estimular de diversas maneiras as chamadas soluções amigáveis/consensuais (AZEVEDO, 2012) para os conflitos de interesse. A proposta de trazê-las para o campo dos conflitos relacionados ao direito à saúde tem ganhado espaço na sociedade em função da promessa de melhor percepção do conflito e consequentemente do encontro da solução mais adequada, pacífica e construída de forma democrática. Segundo Soares (2017), “esses modelos alternativos de resolução de conflitos tais como diálogos institucionais, mediação, conciliação, arbitragem poderiam ser usados no âmbito extrajudicial, desafogando essa Judicialização das políticas sociais e garantindo maior efetividade às decisões no intuito de se solucionar os conflitos sanitários".

Delduque e Castro (2015), notaram que a solução de controvérsias na saúde vem se dando quase que exclusivamente no âmbito do Poder Judiciário, gerando o fenômeno da judicialização (em vez das demandas de saúde pública serem atendidas, como regra, pela União, pelo Estado ou pelo Município, dentro de suas competências, acabam sendo atendidas pelo Judiciário). Segundo esses autores, essa forma de dirimir conflitos não atende ao Sistema Único de Saúde nem ao próprio órgão julgador. Já Silva e Schulman (2017, p. 294) pontuam que, mesmo quando a solução é consensual mas ocorre dentro do Poder Judiciário, seja antes ou 
durante o processo, geralmente em audiências que são designadas com essa finalidade, isso não evita o acionamento da "máquina que se quer manter à margem da discussão".

São, portanto, vozes que pretendem chamar atenção para o potencial das soluções consensuais e extrajudiciais, como a mediação, supostamente aptas "para a solução de controvérsias, a fim de evitar a necessidade de mobilização do Poder Judiciário", isto é, a judiciliação de conflitos de saúde. Delduque e Castro (2015) propõem uma modalidade específica de mediação, chamada "mediação sanitária", que ocorreria dentro do próprio sistema de saúde. Como justificativa para essa proposta, apontam que a judicilização é causada por conflitos internos ao sistema, por exemplo, impasses entre os entes da federação, entre gestores e equipes de atendimento, dentre outros, e ali devem ser resolvidos, não sendo desejável a sua terceirização para o Judiciário. Interessante notar, contudo, que o problema da efetivação da saúde passa a ser discutido, nessas proposições, como um problema de gestão do sistema, descolado de seu status original de direito assegurado constitucionalmente aos cidadãos (cf. Baptista e Amorim, 2014).

No meio jurídico-processual, a reivindicação por uma utilização mais ampla de formas de solução de conflitos alternativas ou complementares ao Judiciário vem ganhando corpo há cerca de duas décadas e marcou de forma muito significativa o texto do Código de Processo Civil em vigor desde 2016 (Lei 13.105/2015) - destinado a regulamentar os procedimentos utilizados nas ações cíveis - quando conclama todos os "atores processuais" para que estimulem o emprego das soluções consensuais ${ }^{10}$ em juízo. Na mesma linha de pensamento, e ainda no ano de 2015, entrou em vigor a Lei de Mediação, já mencionada, com a proposta de regulamentar o seu emprego não apenas em sede judicial e extrajudicial, inclusive a "autocomposição de conflitos no âmbito da administração pública". Com esse "Marco Legal da Mediação", tal método foi revestido de maior segurança jurídica, podendo ser empregado em diferentes espaços e conduzido por profissional capacitado com formação superior em qualquer área ou, no caso da mediação extrajudicial, pessoa capaz que goze da confiança das partes.

\footnotetext{
${ }^{10} \mathrm{CPC}$, art. $3^{\text {o: }}$ "Não se excluirá da apreciação jurisdicional ameaça ou lesão a direito", complementado pelo seu § 3o: "a conciliação, a mediação e outros métodos de solução consensual de conflitos deverão ser estimulados por juízes, advogados, defensores públicos e membros do Ministério Público, inclusive no curso do processo judicial" (BRASIL, 2015).
} 
Na pesquisa não encontramos referência expressa à preocupação dos seus idealizadores ou entidades parceiras em buscarem amparo legal para respaldarem as suas práticas, embora haja referência a práticas de mediação e de conciliação no âmbito da Câmara, quando os seus representantes são chamados a explicar como ela funciona. Mas ficou claro que a já mencionada Resolução 125/2010 do CNJ e os movimentos institucionais que a ela se seguiram acabaram criando o contexto que permitiu a proposição da Câmara (inaugurada em 2013), eis que os Juízes e os Tribunais passaram a apoiar maciçamente a utilização da mediação e da conciliação como alternativas à jurisdição. Inclusive empregando como um argumento recorrente, repetido à exaustão, na literatura especializada, o fato dos Tribunais estarem assoberbados (v.g. PANTOJA, 2008). Esse impulso institucional foi determinante para que tais métodos consensuais viessem a ser contemplados nas leis acima mencionadas, como mais ênfase do que jamais havia ocorrido no país (NUNES, 2014).

Tal opção legislativa parece ter absorvido a percepção de que a atividade de mediação é, antes de mais nada, uma prática a ser desenvolvida por meio da experiência, isto é: um aprender fazendo, aplicável inclusive ao campo da saúde. Iniciativas semelhantes foram observadas em diferentes partes do país. Uma delas foi investigada por Asensi e Pinheiro (2016, p. 51), em parceria com o Conselho Nacional de Justiça, em pesquisa realizada no Município de Lages, Santa Catarina.

Segundo os autores, o Município enfrentava sérias dificuldades no campo da saúde pública, seja pela distância em relação à capital Florianópolis, seja porque "seus recursos são frequentemente desafiados para o fornecimento de serviços e insumos", por força de decisões judiciais. A partir de um consórcio que envolveu vários municípios, evoluiu-se, em 2008, para a assinatura de um Termo de Cooperação Técnica com o Judiciário, com o objetivo de estabelecer estratégias conjuntas de efetivação da saúde. A partir de então, foi estabelecida uma rotina de procedimentos para os processos judiciais referentes às prestações de saúde. Finalmente, em 2012 foi criado um Núcleo de Conciliação de Medicamentos, com o objetivo de disponibilizá-los sem a necessidade de ações judiciais.

No mesmo texto, Asensi e Pinheiro (2016, p. 63) informam que a experiência de Lages foi formada mediante a combinação de aspectos formais (como a judicilização de questões de saúde, embora drasticamente reduzida pelas iniciativas acima) e informais (como o protagonismo do juiz local, entusiasta de soluções inovadoras para os conflitos de interesses). Dentre estas, os autores ressaltam a vivência pessoal e interação entre o juiz e os gestores 
municipais, inicialmente recebida com alguma resistência, mas depois bem absorvida por esses atores. Ao longo do tempo, essa relação informal se traduziu em estratégias extrajudiciais de promoção, prevenção e recuperação da saúde.

Iniciativas dessa natureza são mencionadas como exemplos de como soluções criativas vêm sendo propostas pelos gestores da saúde, com promessa de bons resultados do ponto de vista institucional. Dentre suas vantagens são apontadas a economia e a gestão mais eficiente de recursos públicos alocados à saúde. São propostas que vieram ser reforçadas no âmbito da política judiciária nacional de solução consensual para os conflitos a qual, de certa forma surgiu como uma resposta à judicialização - que não interessa aos gestores nem ao Judiciário, mas que, nos casos de flagrante violação de direitos, pode se apresentar como única alternativa dos usuários do sistema.

\section{MOBILIZAÇÃO INSTITUCIONAL NA GÊNESE E OPERAÇÃO DA CRLS}

A CRLS foi um dos projetos contemplados na edição 2014 do Prêmio Innovare ${ }^{11}$, na categoria advocacia. No sítio eletrônico correspondente ${ }^{12}$ estão registradas as informações mais relevantes sobre essa iniciativa. Informações estas prestadas pelos profissionais que realizaram a inscrição desse projeto para concorrer ao referido Prêmio e que utilizamos como base documental para compreender sua concepção e implantação.

Segundo os dados ali contidos, a iniciativa da CRLS surgiu por ato assinado em maio de 2012 (Convênio de Cooperação nº 003/504/2012), reunindo Procuradores do Estado, Procuradores do Município, Defensores Públicos do Estado, Defensores Públicos da União ${ }^{13}$ e representantes da Secretaria de Estado de Saúde e da Secretaria Municipal de Saúde, com o escopo de promover o atendimento de partes assistidas pela DPGE e pela DPU e que demandassem prestação de serviço de saúde, de modo a evitar o ajuizamento de ações,

11 Segundo sua página oficial (https://www.premioinnovare.com.br/inscricoes), o Prêmio Innovare "tem como objetivo identificar, divulgar e difundir práticas que contribuam para o aprimoramento da Justiça no Brasil. Sua criação foi uma dessas raras oportunidades em que uma conjunção de fatores conspira a favor do bem público". 12 https://www.premioinnovare.com.br/praticas/l/camara-de-resolucao-de-litigios-de-saude-crls 13 De forma simplificada, os Defensores Públicos da União prestam assistência às pessoas carentes nas demandas em que a União seja parte ou tenha interesse no feito, que tramitam na Justiça Federal. Os Defensores Públicos dos Estados atuam em causas que tramitam na Justiça Estadual. 
buscando solução administrativa para oferta de medicamento, agendamento de procedimento cirúrgico ou clínico, internação ou exame médico.

Ainda segundo os proponentes (TAVARES et al, 2014), o crescimento de ações judiciais envolvendo questões de saúde sinalizou que o modelo de atuação dos órgãos do sistema de justiça deveria se adequar a essa nova realidade. As instituições envolvidas enxergaram que o processo judicial, embora seja capaz de impor aos entes públicos obrigações de entrega de medicamentos, internação e a realização de procedimentos, não conseguia atender a dinâmica e a urgência de tratamentos médicos contínuos, segundo os proponentes. Logo, a sua conclusão é que o sistema de justiça deveria criar incentivos para a melhoria da atuação administrativa e não apenas reprimir as suas falhas e, acima de tudo, estruturar rotinas extrajudiciais para solucionar conflitos sanitários.

Ao justificarem sua iniciativa, os proponentes (TAVARES et al, 2014) afirmam que a massificação das demandas judiciais de saúde teria resultado em um processo de concessão indiscriminada de medicamentos por meio de decisões judiciais proferidas em ações individuais, sem que o Sistema de Saúde pudesse avaliar os riscos sanitários das ordens judiciais e o impacto nas políticas públicas em curso. Em dado momento, os proponentes afirmam que:

\begin{abstract}
Nesse cenário, adornado por mandados de prisão de gestores de saúde e ordens judiciais com imposição de multa, em que os interesses do paciente acabavam não atendidos, buscou-se uma aproximação institucional dos atores envolvidos nesses litígios. A CRLS é, pois, o resultado dessa longa aproximação institucional entre as Procuradorias do Estado e do Município do Rio de Janeiro, Secretarias de Saúde do Estado e do Município e Defensorias Públicas. Partindo-se de simples expedientes de solicitação administrativa de medicamentos, dirigidas às Secretarias de Saúde, pela Defensoria Pública do Estado, para evitar o ajuizamento de ações que envolvessem tecnologias já disponíveis no SUS, evoluiu-se para a estruturação de um espaço em que todos os órgãos estão reunidos, potencializando o intercâmbio de informações e tornando mais eficiente o atendimento dos pacientes que tiveram suas demandas desatendidas nas esferas ordinárias do Sistema Único de Saúde (TAVARES et al, 2014).
\end{abstract}

Os proponentes (TAVARES et al, 2014) também pontuaram que a Câmara de Resolução de Litígios de Saúde iniciou suas atividades em 17 de setembro de 2013, mas que, desde 2007, a Procuradoria do Estado e do Município começaram a buscar, a partir do crescimento das demandas judiciais de saúde, a aproximação com os demais atores desses 
processos. Inicialmente, firmou-se com a Defensoria Pública do Estado e com as Secretarias de Saúde do Estado e do Município, uma rotina de envio de ofícios para solicitação de medicamentos incluídos nos programas públicos do SUS, mantendo-se encontros permanentes para otimizar as rotinas dos órgãos, como a inclusão de receitas atualizadas, descrição dos medicamentos por princípio ativo etc. Contam que, em um desses encontros de acompanhamento aventou-se a possibilidade de estruturar um posto de atendimento da SES e da SMS junto ao núcleo de primeiro atendimento da DPGE, de modo que as demandas por exames, cirurgias eletivas e procedimentos clínicos pudessem ser agendados sem o ajuizamento de ações, conforme a disponibilidade da rede de saúde. A partir dessa ideia, em 2011, a PGE, com o apoio da SES, elaborou e desenvolveu uma rotina e fluxo de atendimento do que se denominou Câmara de Resolução de Litígios de Saúde. A ideia da CRLS foi, então, apresentada à DPGE, PGM e SMS e, em setembro de 2011, celebrou-se um protocolo de intenções para criação da CRLS, ainda sem a participação da DPU e do TJRJ.

Com a assinatura do protocolo de intenções, a PGE iniciou a busca por um imóvel que pudesse sediar a CRLS. Com recursos do Fundo Especial da Procuradoria Geral do Estado FUNPERJ, a PGE desapropriou e reformou o imóvel localizado na Rua da Assembleia $n^{\circ} 77$, Centro, Rio de Janeiro. Concomitantemente à reforma do imóvel, a PGE convocou uma reunião com representantes de todos os órgãos signatários do protocolo de intenções e, ainda, de representantes da DPU, AGU, Ministério da Saúde e TJRJ, para celebrar o convênio de cooperação técnica que idealizou. Embora não tenha conseguido sensibilizar a $\mathrm{AGU}$ e o Ministério da Saúde, obteve-se a adesão da DPU e do TJRJ. Assim, em maio de 2012 foi assinado o convênio de cooperação técnica que firmou o funcionamento da CRLS. No ano de 2016 (cf. Soares, 2017, p. 56), foi feito um aditivo ao Termo de Cooperação nr. 003/504/2012, adicionando o Departamento de Gestão Hospitalar (DGH), órgão responsável pelos Hospitais Federais do Ministério da Sáude ${ }^{14}$.

Nota-se, portanto, na concepção e concretização da proposta da CRLS uma efervescente mobilização institucional a qual, ao menos discursivamente, pretende viabilizar solução mais rápida e eficiente para conflitos entre os usuários do sistema de saúde pública atendidos pelas Defensorias Públicas e poderes públicos, no tocante à assistência à saúde, evitando que esses conflitos sejam judicializados. E também se concluiu que a iniciativa foi considerada, do ponto de vista das instituições envolvidas, inovadora e meritória, a tirar pela vasta produção

\footnotetext{
${ }^{14}$ Relato semelhante é apresentado por Souza (2016), em dissertação de mestrado defendida na FGV/Rio.
} 
bibliográfica que lhe dá suporte e pela própria premiação no âmbito do Prêmio Innovare, destinado a reconhecer práticas que contribuem para o aperfeiçoamento do Poder Judiciário no Brasil.

Compreendidas as motivações e o percurso trilhado até que fosse instituída a CRLS, o passo seguinte foi buscar compreender, mais de perto, o seu funcionamento.

\section{COMO SE DÁ O ATENDIMENTO AOS ASSISTIDOS PELA CRLS}

Segundo Matéria divulgada em 11 de novembro de 2013 no sítio Saúde-Jur ${ }^{15}$, auto intitulado "O Portal do Direito da Saúde", reproduzindo dados obtidos da Agência Brasil, a CRLS do Rio de Janeiro teria reduzido em 38\% o número de processos na Justiça contra o setor em todo estado. Segundo a matéria, desde o início de seu funcionamento, cerca de 511 demandas de pacientes teriam sido resolvidas em um período de 30 dias.

A matéria contém uma entrevista com a então coordenadora da Câmara afirmando que, àquela altura, o governo do Rio respondia por 31.000 processos ligados à área de saúde. A maioria das ações, $74 \%$ desse total, havia sido ajuizada nas Varas da Capital do estado do Rio de Janeiro e o restante se referia a casos nos demais municípios. Entre os processos mais comuns, estavam os de pacientes em busca de remédios, cerca de $60 \%$, e leitos para internação.

Segundo a entrevistada, à época, o objetivo da iniciativa era solucionar com mais celeridade a situação desses pacientes que recorrem à Defensoria Pública, sem que eles precisassem ingressar com uma ação judicial. Segundo a coordenadora, essas pessoas só deixavam a CRLS a partir do momento que tivessem certeza que, ao chegar na unidade hospitalar, receberiam o que foi solicitado. "Elas saem com um ofício da Câmara de Resolução com o encaminhamento específico para o local solicitado", ressaltou. Ao todo, são feitos 60 atendimentos por dia e a expectativa - na época, em 2013 - era chegar a 100 consultas diárias.

15 Disponível em https://saudejur.com.br/camara-de-litigios-de-saude-reduziu-processos-em-38/. Acesso em 20 abr. 20. 
Posteriormente a pesquisa apontou que nem todas as demandas são atendidas da forma descrita nas linhas acima, tratando-se de uma matéria jornalística voltada para a divulgação institucional da CRLS. Há usuários que não conseguem ser atendidos em suas demandas, ou há uma demora significativa. Voltaremos a esse ponto mais adiante.

Ainda para compreender a estrutura disponível, de forma complementar, recorremos a informações disponibilizadas pela Secretaria Estadual de Saúde do Rio de Janeiro a respeito da CRLS $^{16}$, dando conta de que a mesma é dotada de uma equipe multidisciplinar com enfermeiros, farmacêuticos, nutricionistas, assistentes sociais e médicos para elaborar pareceres técnicos, de acordo com o quadro clínico apresentado e os tratamentos solicitados.

Soares (2017), em pesquisa que resultou em sua dissertação de mestrado defendida no Programa de Pós-Graduação em Justiça Administrativa da Universidade Federal Fluminense, observou e descreveu em detalhes a atuação da Câmara de Resolução de Litígios de Saúde (CRLS) e procurou compreender a forma como busca resolver, extrajudicialmente, conflitos sanitários. A autora apresenta um passo-a-passo do atendimento prestado aos usuários na CRLS (SOARES, 2017, p. 59 e p. 97), explicando que se iniciam pela triagem que é realizada por assistentes sociais. Após uma avaliação inicial do caso, ocorre o atendimento propriamente dito, que é feito pelos atendentes das Defensorias Públicas e por fim, o usuário é direcionado para a análise técnica do direito à saúde pleiteado, que é feita pelos profissionais das Secretarias de Saúde. Caso a demanda não seja satisfeita, o usuário é encaminhado a um novo atendimento realizado pela equipe multiprofissional das Defensorias e das Secretarias onde é efetivado o encaminhamento administrativo ou fica decidido o ajuizamento da ação judicial Soares (2017, p. 59).

Embora não haja um registro da temporalidade desses sucessivos atos seja no trabalho retro citado, seja nas manifestações institucionais consideradas na pesquisa, nossas observações de campo permitiram inferir que não há prazos rigidamente definidos para que cada uma dessas etapas seja ultimada, pois isso vai depender de cada caso, em vista da providência solicitada pelo usuário (medicamento, insumo, cirurgia, movimentação); da disponibilidade do ente público encarregado de providenciar o atendimento do pleito, dentre outros. Nessa linha de pensamento, a inexistência de regras de procedimento de natureza compulsória - no que pertine 
a prazos, por exemplo - pode se tornar um obstáculo para o usuário, pois pode ser longa a espera para obter o atendimento de sua demanda pela via extrajudicial, a despeito de todas as promessas e notícias propaladas pelas instituições envolvidas na criação e operação da CRLS.

Segundo matéria divulgada no site da Defensoria Pública do Estado do Rio de Janeiro em 24 de outubro de $2017^{17}$, a proposta de solução extrajudicial de conflitos de saúde mostrouse uma experiência bem sucedida e ganhou novo fôlego no ano de 2015, por meio do projeto "Construindo o SUS com a Defensoria Pública do Estado do Rio de Janeiro", quando Câmara passou a ser replicada nos municípios do interior do estado do Rio de Janeiro (o mesmo em SOARES, 2017, p. 56) ${ }^{18}$.

Pelo fato de ser a CRLS pioneira e de situar-se no centro do Rio de Janeiro com uma boa estrutura, a opção da pesquisa foi pela aproximação empírica da Câmara sediada na Rua da Assembleia, sendo esta a experiência de campo que passaremos a relatar nas linhas seguintes.

\section{ALGUMAS PERPLEXIDADES EMPÍRICAS}

No conhecido texto "O Trabalho do Antropólogo: Olhar, Ouvir e Escrever" (1996, p. 19-21), Cardoso de Oliveira explica que há, na literatura etnológica, uma longa e arraigada tradição sobre a relação entre entrevistador e entrevistado, objeto de muitos estudos e considerações célebres, como em Malinowski. E explica que, no ato de ouvir o informante, o etnólogo exerce um poder enorme sobre ele, ainda que pretenda se posicionar como o observador mais neutro possível, buscando uma maior objetividade para a pesquisa. Essa influência vai desempenhar, segundo o autor, um efeito profundamente empobrecedor do ato cognitivo, motivo pelo qual o informante deve se transformado em interlocutor, quando uma

17 Conteúdo disponível em: <http://www.defensoria.rj.def.br/noticia/detalhes/5102-DPRJ-modelo-de-atuacaoextrajudicial-podera-ser-adotado-no-exterior $>$. Acesso em 07 mai. 20.

18 No site da Defensoria Pública do Estado consta que existem CRLS em vários municípios do estado do Rio, devendo ser observadas pelos assistidos as regras específicas que foram estabelecidas por cada uma delas, conforme listagem abaixo: capital, Belford Rocho, Bom Jardim, Japerí, Nilópolis, Nova Friburgo, Nova Iguaçú, Mesquita, São João de Meriti, Magé, Silva Jardim, Paty do Alferes, Miguel Pereira, Campos dos Goytacazes, Vassouras. Informações
$<$ http://sistemas.rj.def.br/publico/sarova.ashx/Portal/sarova/imagem<http://sistemas.rj.def.br/publico/sarova.ashx/Portal/sarova/imagemdpge/public/arquivos/C\%C3\%A2maras_de_Resolu\%C3\%A7\%C3\%A3o_de_Lit\%C3\%ADgio_de_Sa\%C3\%BA de.pdf. Acesso em 05 mai. 20. 
nova modalidade de relacionamento pode ter lugar. Essa lição mostrou-se extremamente útil e buscamos aplicá-la nesta pesquisa.

Ao compreender as posições institucionais acerca do projeto CRLS, já explicitadas, percebemos que entrevistas com as autoridades e instituições ligadas a essa iniciativa poderiam apresentar apenas "mais do mesmo", ou seja: a visão institucional sobre a Câmara, o discurso justificador, a história, as parcerias firmadas, e como a iniciativa estaria supostamente contribuindo para reduzir o número de ações ajuizadas no campo da saúde pública etc. Por outro lado, Souza (2016) e Soares (2017) já haviam privilegiado essa aproximação institucional.

Logo, nossa opção foi por realizar uma aproximação de inspiração etnográfica, quando procuramos, em visitas realizadas à CRLS, observar e interagir, buscando alcançar ao mais possível, as percepções dos seus usuários. Durante nossas incursões de campo, ocorridas em três oportunidades entre maio de 2019 e março de 2020, percebemos que se trata de instalações, aparentemente, bastante apropriadas. Inclusive com a peculiaridade de que o ponto escolhido encontra-se razoavelmente próximo das sedes das instituições parceiras, sendo também de fácil acesso para quem se encontra no centro da cidade, ou que pode ter acesso a ele pelos meios de transporte disponíveis ${ }^{19}$.

Nessas incursões chamou nossa atenção o fato de haver em todo lugar cartazes e pinturas nas paredes contendo palavras alusivas às vantagens que a mediação e outras formas consensuais de solução de conflitos podem apresentar, quando comparadas ao caminho judicial. Tais mensagens apregoavam que a melhor forma de resolver uma demanda ligada à saúde pública seria buscando uma solução consensual, deixando de ajuizar uma ação judicial. Essa mensagem está implícita em frases tais como "Lugar que busca um meio para resolver conflitos de saúde de forma simplificada, eficaz, rápida e satisfatória - Câmara de Resolução de Litígios de Saúde" (anotações feitas a mão na sede da CRLS-Rio, em 19/02/20).

Há também, gravadas nas paredes, as palavras:

\footnotetext{
${ }^{19}$ Na prática são observadas as regras de divisão do trabalho da Defensoria pública que atende os assistidos em postos espalhados pelo Estado do Rio, em vista do local de residência dos assistidos. Daí porque é solicitado o comprovante de residência no momento do atendimento. Essa exigência, por sinal, é observada à risca pela equipe de atendimento, como pude constatar em minhas incursões de campo.
} 
Diálogo. Vontade. Reconstrução. Comunicação. Agilidade. Colaboração. Solução. Entendimento. Exxito. Clareza. Confiança. Saúde. Empatia. Coerência. Parceria. Colaboração Eficácia da Solução. Paciência. Informação. Reformulação. Persistência. Comunicação. Agilidade. Orientação. Informação. Sabedoria (anotações feitas a mão na sede da CRLS-Rio, em 19/02/20).

Essas “palavras de ordem” estão impressas dentro do prédio da CRLS, em locais bem visíveis, inclusive nas faces dos degraus da escada que, a partir do plano da rua, dá acesso ao setor de primeiro atendimento situado no subsolo. De modo que uma pessoa sentada na sala de espera do primeiro atendimento, ao olhar para a direita, em direção à escada, se depara com essas mensagens alusivas à promessa - por assim dizer - que as entidades idealizadoras da CRLS fazem ao jurisdicionado/assistido que está em busca de uma solução (remédio, exame, cirurgia, tratamento) para o seu problema de saúde, no sentido de que todos, inclusive o próprio assistido da Defensoria, usuário do SUS, devem colaborar com a obtenção de uma solução consensual, evitando o ajuizamento de ações. Algo que será problematizado em considerações finais.

Na apresentação do projeto CRLS para o prêmio Innovare (TAVARES et al, 2014), os proponentes informaram que o imóvel-sede foi estruturado com o cuidado de proporcionar um ambiente acolhedor, com profissionais treinados para lidar com as dificuldades inerentes à sensibilidade das demandas recebidas, tendo-se, inclusive, elaborado projeto de cromoterapia, isto é, utilização de cores adequadas nas instalações, para proporcionar um ambiente favorável ao acordo $^{20}$. Com efeito, nos manuais que se propõem a orientar sobre boas práticas de mediação, aplicáveis a outros ambientes destinados à solução consensual de conflitos, o cuidado com o ambiente - que deve ser calmo, acolhedor - é um dos aspectos mais ressaltados (cf. AZEVEDO, 2012; BRAGA NETO, 2012 e MIRANDA NETTO et al, 2015).

O subsolo/primeiro atendimento também é acessível por meio de um elevador disponível a poucos metros da entrada, sendo que as regras de acessibilidade parecem ter sido observadas, trando-se de um local limpo, bem sinalizado e bem cuidado. Após a triagem, é nos andares superiores que os assistidos são atendidos em suas demandas pelas

20 Conferir em <https://www.premioinnovare.com.br/praticas/l/camara-de-resolucao-de-litigios-de-saude-crls>. Ver item: Quais os fatores de sucesso da prática? 
equipes institucionais. Tudo apontando para o caminho do consenso, em vez do caminho judicial.

Curiosamente esse mesmo "recado" aparece também nas páginas institucionais dos entes parceiros como, por exemplo, no site do próprio Tribunal de Justiça do Estado do Rio de Janeiro, órgão judiciário encarregado de julgar as ações ajuizadas pelos cidadãos em face do Município e/ou do Estado do Rio reivindicando alguma providência no campo da saúde pública. Notícia publicada no site do TJERJ pela sua assessoria de imprensa em outubro de 2015 enaltecia uma série de iniciativas levadas a efeito pelo governo do Estado do Rio de Janeiro criando uma "estrutura própria para atender casos de saúde que chegam à Justiça"21. Dentre as iniciativas apontadas, a matéria fez referência às CRLS, destacando uma suposta economia de recursos públicos e pontuando que "a ideia é buscar soluções administrativas para o atendimento de cidadãos que precisam de medicamentos, exames, internações, tratamentos e transferências do SUS, evitando o ajuizamento de ações".

O verbo "evitar" é significativo no contexto da notícia, reforçando a ideia de que uma ação judicial é algo a ser repelido, afastado a todo custo, sendo substituída a atuação do juiz por outras instâncias. Ou, pelo menos, criando etapas que devam ser vencidas previamente para que, somente após, o magistrado possa ser acessado por meio do devido processo legal, quando o pleito não é atendido no âmbito administrativo. Estratégia que, por sinal, foi adotada de forma análoga no Código de Processo Civil de 2015 (art. 334) prevendo que o juiz, ao receber uma petição inicial (documento que se presta a iniciar uma nova ação de natureza cível) deve designar uma audiência de mediação ou de conciliação, a ser conduzida por mediadores e conciliadores. Nessa linha de pensamento, a estratégia é criar instâncias de atendimento que precisam ser superadas para que, somente após, se possa acessar a figura do magistrado.

A CRLS, de forma análoga, é uma nova instância preenchida com uma série de procedimentos pertinentes ao protocolo de atendimento já descrito linhas acima, que o usuário deve percorrer. No casos em que o pedido é atendido administrativamente em um prazo razoável, pode-se entender que a Câmara serve para aproximar o usuário daquele ente público

21 Conferir notícia publicada no site do Tribunal de Justiça do Estado do Rio de Janeiro pela sua assessoria de imprensa, no site www.tjrj.jus.br, na data de 28/10/2015, sob o título "Rio cria estrutura própria para atender casos de saúde que chegam à Justiça". 
que deve prestar o atendimento à saúde. Nessas hipóteses, aproximam-se o discurso institucional e a prática.

Entretanto, quando o pedido não é atendido em tempo razoável, ou quando o usuário tem a sua pretensão frustrada, a Câmara se revela como uma etapa administrativa adicional que precisa ser vencida antes do ajuizamento de uma ação judicial adequada para obrigar o inadimplente (União, Estado ou Município a quem compete a prestação almejada) a cumprir a sua obrigação. Logo, em tais casos, a despeito da aproximação entre usuários e administração, amplia-se a distância entre o jurisdicionado (usuário do sistema de justiça) e o Judiciário, movimento este que veio embalado em um discurso contundente, apontando que a solução consensual é sempre melhor opção para resolver qualquer tipo de conflito, em qualquer situação - afirmação que não resiste a uma verificação empírica.

A própria assertiva, do senso comum, de que "um mau acordo é sempre melhor que uma boa demanda" pode ser problematizada. Quanto tempo a solução consensual tardará para chegar? Todas as demandas submetidas à CRLS são necessariamente atendidas? Os acordos serão cumpridos? Os entes públicos estão dispostos a atenderem as prescrições específicas do médico que acompanha o paciente? São perguntas cuja resposta pode variar de um caso para o outro.

Para ilustrar a forma como eventualmente, a proposta pode fragilizar quem já se encontra em posição de vulnerabilidade neste cenário, vamos citar um exemplo baseado em nossas percepções empíricas na CRLS. Em uma das interações mantidas no campo, um senhor, mulato, com cerca de 50 anos, entrou na sala de espera caminhando com dificuldade. Ele vestia roupas bem simples, bermuda, camiseta e chinelos. Em entrevista informal ele relatou que tinha um problema de hérnia de disco, com recomendação médica de cirurgia. Disse que já havia sido celebrado um acordo dentro da CRLS mas que, até aquele momento, passados cerca de 4 meses, a cirurgia ainda não fora marcada. "O acordo foi no ano passado, mais ou menos em outubro, novembro.... e até agora nada..." - comentou. Ele pareceu desanimado, mas disse acreditar que deveria insistir em resolver o problema ali mesmo, de forma consensual. Pode-se especular se uma ordem judicial, contendo o pedido de uma tutela de urgência (para obrigar o ente público a um atendimento imediato do pleito, sob pena de multa), não poderia ter sido capaz de dar cabo do impasse com maior rapidez. 
Soares (2017) levantou que expressivo percentual de solicitações que chegam à CRLS são atendidas, levantamento este que vem ao encontro das falas institucionais. Mas também constatou o que era evidente: além dos pleitos atendidos pela CRLS, os quais são considerados casos de sucesso, amplamente divulgados pelas entidades envolvidas na instalação e gestão da CRLS, há aqueles que não são atendidos, por diferentes motivos. Por exemplo, das 248 transferências de pacientes que foram solicitadas à CRLS entre 2014 e meados de 2016, apenas 42 (quase 17\%) foram obtidas de forma administrativa. No mesmo período, dos 81 tratamentos buscados, 37 foram encaminhados administrativamente. Com relação a medicamentos, dos 3.495 solicitados, 1.526 foram disponibilizados pelas unidades de saúde pública (pouco mais de 43\%). E dos 780 insumos solicitados, apenas 309 foram conseguidos na CRLS (SOARES, 2016, p. 83-84) ${ }^{22}$.

Ocorre que, por se tratar de uma iniciativa institucional que visa conter a judicialização da saúde, dados como estes acima, que justificam plenamente a propositura de ações pelos usuários que tiveram a sua pretensão desatendida na CRLS, não são apresentados de forma clara e transparente. Pelo contrário, não notamos interesse das entidades envolvidas em divulgar qualquer informação que pudesse, minimamente, colocar sob questão ou desabonar o trabalho realizado na Câmara. Essa postura é questionável, já que qualquer política pública contém imperfeições e precisa ser objeto de constante reavaliação para redirecionamentos e aperfeiçoamento contínuo.

Em trabalho científico em que buscaram examinar a satisfação dos usuários com a Assistência Primária à Saúde (APS), Gomide et al (2018, p. 395) apontaram que a demora no agendamento e atendimento de consultas na APS e o não atendimento da demanda espontânea são os principais fatores para a baixa satisfação dos usuários. A humanização do cuidado também repercutiu para a qualidade da atenção à saúde. Quando o usuário não se sentiu acolhido e ouvido, e nem ao menos foi submetido ao exame físico, avaliou mal o cuidado recebido, nesses serviços de APS, nos limites da pesquisa realizada por aqueles autores. Logo, uma demora exagerada no atendimento de um pleito, sobretudo se já foi objeto de acordo, seria

\footnotetext{
${ }^{22}$ É importante explicar que os medicamentos e insumos não são entregues ali, mas sim mediante encaminhamento que é feito para uma determinada unidade de saúde, aumentando o caminho a ser percorrido e as chances de serem frustradas as expectativas de quem depende do atendimento público de saúde no Rio de Janeiro.
} 
motivo de insatisfação, contribuindo para uma tomada de decisão quanto ao ajuizamento de uma ação, tratando-se de um direito dos usuários.

\section{CONSIDERAÇÕES FINAIS}

A despeito desses estranhamentos, foi e vem sendo edificada ao longo do tempo uma sólida base teórica para respaldar iniciativas como esta, da CRLS. Delduque e Castro (2015), já mencionados linhas acima, evidenciam uma percepção positiva acerca do que denominam "Mediação Sanitária". Para esses autores, os Modelos Alternativos de Resolução de Conflitos representam a adesão ao que denominam de "cultura da pacificação", em oposição à cultura que, segundo os autores, gira em torno da necessidade de uma decisão judicial para que uma controvérsia possa ser resolvida. Segundo eles, a solução pacífica é sempre preferível, inclusive economicamente, deixando a busca do aparato Judicial como uma última possibilidade.

Esses mesmos argumentos são frequentemente invocados pelos entusiastas da mediação de conflitos para estimular na sua disseminação, como se vê, por exemplo, em Pinho e Paumgartten (2015). Pode-se questionar, contudo, se a mesma lógica que pode nortear a solução de conflitos entre particulares, envolvendo direitos disponíveis (uma soma em dinheiro ou a venda de um automóvel, por exemplo) também serve para dirigir a tomada de decisões nas relações entre os particulares e o Estado, sobretudo envolvendo interesses de pessoas pobres e doentes, ou suas famílias, como ocorre na CRLS.

A despeito de todas as boas intenções de que a iniciativa se reveste, a própria proposta da CRLS pode ser problematizada porque, em alguns momentos, repele com grande veemência a busca pela prestação jurisdicional - o ajuizamento de um ação judicial - como se o acesso ao Judiciário não fosse, ele próprio, um direito assegurado Constitucionalmente. Nessa medida, forma-se um paradoxo porque as instituições ali presentes são responsáveis pela promoção de direitos dos usuários. Inclusive as Defensorias Públicas estarão institucionalmente encarregadas do ajuizamento das respectivas ações judiciais, caso o usuário não deseje tentar uma solução consensual, ou quando esta se mostrar inviável. 
Essas percepções podem ser problematizadas à luz das reflexões da antropóloga americana Laura Nader (1994), com vasta experiência em pesquisa sobre formas consensuais de administração de conflitos. Ela percebeu que, de forma geral, em uma disputa, a parte mais fraca prefere a intervenção de um juiz imparcial e forte o bastante para impor suas decisões, ao passo em que os mais poderosos preferem negociar, pois têm maior poder de barganha. Não obstante, em vários momentos e lugares estudados por diferentes antropólogos que a antecederam em suas pesquisas, uma certa ideologia se fez perceber, apontando caminhos contrários e reduzindo a proteção de grupos vulneráveis.

Este discurso, que propomos denominar de "discurso da harmonia" (remetendo, de forma proposital, às pesquisas de NADER, 1994) pode causar algum desconforto ou estranhamento quando se percebe que as pessoas assistidas pela CRLS estão à espera do atendimento de demandas no campo da saúde pública, algumas delas inadiáveis mas que, muitas vezes, são rechaçadas ou atendidas tardiamente, a despeito das tentativas anteriores em sede administrativa, ou mesmo dos acordos celebrados na própria Câmara.

Nessa ótica, a sugestão de que deve haver "paciência" e "persistência", bem como "colaboração" e "diálogo" despertam perplexidade por estar-se tratando de um direito violado, e de um conflito envolvendo particulares, de um lado, e o ente público, do outro, sendo evidente a vulnerabilidade do cidadão, sobretudo dos pobres e doentes, diante de todo o aparato estatal que, ao fim e ao cabo, permitiu que entidades que ocupariam posições dispares no cenário processual acabem se tornando "parceiras" (a Defensoria Pública e a Procuradoria do Estado, por exemplo, que estariam em lados opostos da "arena" processual, no caso de ser ajuizada alguma ação).

De certa forma, trata-se de relativizar uma garantia processual de natureza constitucional, o devido processo legal, que, no Brasil, nem sempre serve para proteger o cidadão do Estado, mas sim o Estado do cidadão, como perceberam Baptista e Amorim (2014). O caso das CRLS parece afinar-se bastante a esse diagnóstico principalmente porque se trata de uma imposição dos entes públicos envolvidos na gestão da saúde no Rio de Janeiro, não havendo notícia de envolvimento dos usuários no processo de concepção, instalação e funcionamento da CRLS, nem pesquisas acadêmicas voltadas para compreender a percepção dos usuários desse serviço. 
Essa percepção “inovadora" sobre os papéis que cada uma das instituições envolvidas na operação da CRLS tem a desempenhar nesse cenário é, contudo, enxergada de forma positiva pelos gestores da saúde pública (conferir ASENSI e PINHEIRO, 2016; SILVA e SCHULMAN, 2017), bem como aparece e é naturalizada na proposta submetida pelos idealizadores da CRLS ao Prêmio Innovare, quando explicam que "a posição adversarial nas demandas judiciais acabava por colocar os órgãos (Defensorias, Procuradorias, Secretarias de Saúde) em contraposição, quando, a toda evidência, os interesses convergem para a satisfação e concretização do direito social à saúde", e ainda que "A reunião em um espaço físico de todos os atores envolvidos nessas demandas sanitárias foi um fator determinante para o sucesso da prática, a partir da compreensão mútua das realidades institucionais e das visões distintas acerca do melhor modo de atendimento dos assistidos/pacientes."

Nader pontua como a harmonia coercitiva foi utilizada como método para silenciar povos que, em diferentes momentos da história, dentro de sua pesquisa, reagiram de maneira enfática/irada diante de certos conflitos. Concluiu ser altamente provável que a ideologia da harmonia faça parte do sistema de controle hegemônico que se espalhou pelo mundo todo com a colonização política europeia e a evangelização cristã. E também observou um contexto de apelo ao consenso para pacificar as massas nos movimentos dos anos 60 que lutaram por direitos em geral e para, de algum modo, esfriar os protestos pela guerra no Vietnã, nos EUA.

Dentro do recorte considerado, as situações descritas acima, a respeito da proposta e funcionamento da CRLS, representam uma redescoberta dessa ideologia da harmonia, que funciona de um lado como discurso de justificação das iniciativas institucionais analisadas neste trabalho e, de outro lado, como forma de apaziguar os ânimos dos mais exaltados, convencendoos de que vale a pena esperar por soluções consensuais, ainda que demorem ou que sejam necessários ajustes que permitam harmonizar o seu pleito em vista dos (para muitos) incompreensíveis desígnios do ente estatal. Ou mesmo que seja necessário adiar o acesso ao Judiciário, a despeito deste ser reconhecido como um Direito de todo cidadão brasileiro.

As oscilações entre o modelo da harmonia e o modelo do conflito na abordagem das disputas foram descritas por Nader e parece que a estruturação, pelo Estado, de modelos alternativos para a solução de disputas se presta, em alguma medida, a acalmar os receios de conflito - no caso, conflitos envolvendo os usuários e os serviços de saúde, sabidamente incapazes de dar conta, no Brasil, de toda a demanda em condições dignas. É preciso que esses modelos sigam sendo objeto de reavaliação e aperfeiçoamentos constantes, para que possam 
servir como mecanismos que garantam o efetivo acesso da população, sobretudo os mais pobres e doentes, aos seus direitos constitucionalmente assegurados.

\section{REFERÊNCIAS BIBLIOGRÁFICAS}

ASENSI, Felipe Dutra; PINHEIRO, Roseni (Coords.). Judicialização da saúde no Brasil: dados e experiências. Brasília: Conselho Nacional de Justiça, 2015

ASENSI, Felipe Dutra; PINHEIRO, Roseni. Judicialização da Saúde e Diálogo Institucional: a experiência de Lages (SC). Revista De Direito Sanitário, 17(2), 2016, 48-65. https://doi.org/10.11606/issn.2316-9044.v17i2p48-65

AZEVEDO, André Gomma de (Org.). Manual de Mediação Judicial. Brasília/DF: Ministério da Justiça e Programa das Nações Unidas para o Desenvolvimento. Brasil. 2012.

BAPTISTA, Bárbara Gomes Lupetti; AMORIM, Maria Stella de. Quando direitos alternativos viram obrigatórios: burocracia e tutela na administração de conflitos. Antropolítica Revista Contemporânea de Antropologia, n. 37, 2014. Disponível em: <https://app.uff.br/riuff/bitstream/1/11277/1/263-552-1-SM.pdf>. Acesso em 25 ago. 2020.

BAPTISTA, Barbara Gomes Lupetti. Os Rituais Judiciários e o Princípio da Oralidade. Porto Alegre: Editora Sergio Antônio Fabris, 2008.

BRAGA NETO, Adolfo. Mediação de Conflitos: Conceito e Técnicas. In: LORENCINI, Marco Antônio Garcia Lopes; SALLES, Carlos Alberto de; SILVA, Paulo Eduardo Alves da (Coord.). Negociação, Mediação e Arbitragem: Curso básico para programas de graduação em Direito. Rio de Janeiro: Forense, 2012. pp. 103-125.

BRASIL. Conselho Nacional de Justiça. Resolução $\mathbf{n}^{\mathbf{0}}$ 125/2010. Disponível em: <http://cnj.jus.br/programas-e-acoes/conciliacao-mediacao/legislacao>. Acesso em 02 mar. 2015.

BRASIL. Decreto nr. 8.243/2014 - Institui a Política Nacional de Participação Social - PNPS e o Sistema Nacional de Participação Social - SNPS, e dá outras providências. Disponível em: $<$ https://presrepublica.jusbrasil.com.br/legislacao/120466065/decreto-8243-14>. Acesso em 10 mai. 20.

BRASIL. Lei $\mathbf{n}^{\mathbf{0}}$ 13.105/2015 - Código de Processo Civil. Disponível em <http://www.planalto.gov.br/ccivil_03/_Ato2015-2018/2015/Lei/L13105.htm>. Acesso em: 18 mar. 2015.

BRASIL. Lei no 13.140/2015 - Dispõe sobre a mediação entre particulares como meio de solução de controvérsias e sobre a autocomposição de conflitos no âmbito da administração pública. Disponível em <http://www.planalto.gov.br/ccivil_03/_ato20152018/2015/lei/113140.htm>. Acesso em 01 mai. 2018. 
DELDUQUE, Maria Célia; CASTRO, Eduardo Vasquez de. A Mediação Sanitária como alternativa viável à judicialização das políticas de saúde no Brasil. Revista Saúde em Debate. Rio de Janeiro, v. 39, n. 105, p.506-513, abr.-jun. 2015. DOI: 10.1590/0103110420151050002017. Acesso em 05 jun. 2020.

DUARTE, Fernanda; IORIO FILHO, Rafael Mario; FELIPE, Ana Paula Faria; MEIRELLES, Delton. Mediações: discursos, práticas e reflexões. Niterói: PPGSD/UFF, 2017.

ESPERIDIÃO, Monique; TRAD, LenyAlves Bonfim. Avaliação de Satisfação de Usuários. Revista Ciência e Saúde Coletiva, 10 (Sup), 303-312, $2005 . \quad$ DOI: https://doi.org/10.1590/S1413-81232005000500031.

FILPO, Klever Paulo Leal. Mediação Judicial: Discursos e Práticas. Rio de Janeiro: Mauad X e FAPERJ, 2016.

GOMIDE, Mariana Figueiredo Souza et al. A Satisfação do Usuário com a Atenção Primária à Saúde: uma análise de acesso e acolhimento. Interface (Botucatu). 2018; 22(65):387-98. DOI: 10.1590/1807-57622016.0633. Acesso em 01 mai. 2020.

KANT DE LIMA, Roberto. Por uma Antropologia do Direito, no Brasil. In: Ensaios de Antropologia e de Direito. KANT DE LIMA, Roberto; MISSE, Michel. (Coord.). Rio de Janeiro: LumenJuris, 2009.

MALINOWSKI, Bronislaw. Argonautas do Pacífico Ocidental: um relato do empreendimento e da aventura dos nativos nos arquipélagos da Nova Guiné melanésia. São Paulo: Abril Cultural, 1978.

MEIRELLES, Delton Ricardo Soares; MIRANDA NETTO, Fernando Gama de. Reflexões sobre a conciliação e a mediação civil no âmbito judicial e extrajudicial. In: MUNIZ, Joaquim de Paiva et al. (Coord.). Arbitragem e mediação: temas controvertidos. Rio de Janeiro: Forense, 2014.

MELLO, Kátia Sento Sé; BAPTISTA, Bárbara Gomes Lupetti. Mediação e Conciliação no Judiciário: Dilemas e Significados. Dilemas - Revista de Estudos de Conflitos e Controle Social. IFCS/UFRJ. Rio de Janeiro. v.4, n. 1, jan./mar. 2011.

MIRANDA NETTO, Fernando Gama de; SOARES, Irineu Carvalho de Oliveira. Princípios procedimentais da mediação no novo Código de Processo Civil. In: ALMEIDA, Diogo Assumpção Rezende de; PANTOJA, Fernanda Medina; PELAJO, Samantha (Coord.). A mediação no novo Código de Processo Civil. Rio de Janeiro: Forense, 2015.

NADER, L. Harmonia coerciva: a economia política dos modelos jurídicos. Revista Brasileira de Ciências Sociais, São Paulo, ano 9, n. 29, p. 18-29, 1994. Disponível em: <http://www.anpocs.org.br/portal/publicacoes/rbcs_00_26/rbcs26_02.htm>. Acesso em: 19 jan. 2016.

NUNES, Thais Borzino Cordeiro. A conciliação nas ações fazendárias: perspectivas teóricas e obstáculos empíricos para a sua efetiva implementação. 2014. Monografia (Graduação em Direito) - Faculdade de Direito, Universidade Católica de Petrópolis, Petrópolis. 
OLIVEIRA, Roberto Cardoso de. O Trabalho do Antropólogo: Olhar, Ouvir, Escrever. Revista de Antropologia, São Paulo, USP, 1996, v. 39, n. 1. Disponível em: < file://C:/Users/Klever/Downloads/111579-Texto\%20do\%20artigo-201293-1-10-

20160229\%20(4).pdf>. Acesso em 07 mar. 20.

PANTOJA, Fernanda Medina. Da Mediação Incidental. In: PINHO, Humberto Dalla Bernardina de (Coord.). Teoria Geral da Mediação à Luz do Projeto de Lei e do Direito Comparado. Rio de Janeiro: Lumen Juris, 2008, pp.185-240.

PEIRANO, Mariza. Etnografia não é Método. Horizontes Antropológicos, vol. 20, n. 42, Porto Alegre, jul./dez. 2014. Disponível em < http://dx.doi.org/10.1590/s0104$71832014000200015>$. Acesso em 25 ago. 2020.

PINHEIRO, Roseni; MARTINS, Paulo Henrique (Org.). Avaliação em saúde na perspectiva do usuário: abordagem multicêntrica. Rio de Janeiro: Cepesc, 2011. 376p.

PINHO, Humberto Dalla Bernardina de; PAUMGARTTEN, Michele Pedrosa. Os desafios para a integração entre o sistema jurisdicional e a mediação a partir do novo Código de Processo Civil. Quais as perspectivas para a justiça brasileira: In: ALMEIDA, Diogo Assumpção Rezende de; PANTOJA, Fernanda Medina; PELAJO, Samantha (Coord.). A mediação no novo Código de Processo Civil. Rio de Janeiro: Forense, 2015.

ROMANELI, Luciana Caramore; BAPTISTA, Bárbara Gomes Lupetti. As múltiplas formas de solução de conflitos na Favela da Rocinha: uma visão empírica da mediação comunitária. Trabalho apresentado no Encontro Nacional de Antropologia do Direito (ENADIR), 2017.

SILVA, Alexandre Barbosa da; SCHULMAN, Gabriel. (Des)Judicialização da Saúde: Mediação e Diálogos Institucionais. Revista Bioética (impressa). 2017, n. 25 (2), pp. 290-300. DOI: http://dx.doi.org/10.1590/1983-80422017252189.

SOARES, Flávia Dantas. A atuação da Câmara de Resolução de Litígios de Saúde (CRLS) na Resolução Extrajudicial dos Conflitos Sanitários: um estudo nos anos de 2014 a 2016. Dissertação apresentada ao Programa de Pós-Graduação em Justiça Administrativa da Universidade Federal Fluminense. Niterói, 2017.

SOUZA, Anderson Monteiro de. A Atuação em Rede de Instituições Governamentais na Resolução de Conflitos sobre Demandas Sanitárias no Rio de Janeiro. Dissertação de Mestrado apresentada à Fundação Getúlio Vargas no Curso de Mestrado Profissional em Administração Pública. Rio de Janeiro, 2016.

TAVARES, Lucia Lea Guimarães; GRYNBERG, Cyro; MARCARENHAS, Rodrigo; PALHEIRO, Pedro Henrique di Masi; GOMES FILHO, Hugo Gonçalves; SARAIVA, Maria Luiza de Luna. Descrição da Câmara de Resolução de Litígios de Saúde para concorrer ao Prêmio Innovare 2014, na categoria advocacia. Informações disponíveis em: $<$ https://www.premioinnovare.com.br/praticas/l/camara-de-resolucao-de-litigios-de-saudecrls>. Acesso em 07 abr. 2020. 